\title{
Evaluating pollution degree of oil spills on the sea surface
}

\author{
ZHOU Xuan ${ }^{1 *}$, KOU Jie ${ }^{2}$, CHAO Hao ${ }^{3}$ and WANG Taiyang ${ }^{4}$ \\ ${ }^{1}$ BaiLie School of Petroleum Engineering, Lanzhou City University, Lanzhou, China \\ ${ }^{2}$ Shandong Key Laboratory of Oil \& Gas Storage and Transportation Safety, China University of Petroleum (East China), Qingdao, China \\ ${ }^{3}$ China Resources (Zhengzhou) Municipal Engineering Design \& Research Insititute Co.Ltd, Zhengzhou, China \\ ${ }^{4}$ Engineering Dept., East China Engineering Science and Technology Co.Ltd, Hefei, China
}

\begin{abstract}
This article analyses influencing factors of pollution degree of oil spills on the sea surface and establishes corresponding evaluation system, thus combines fuzzy comprehensive evaluation method and analytic hierarchy process to evaluate pollution degree of oil spill accidents in the Bohai Sea. Based on the evaluation system, oil spill accidents in Penglai 19-3 oilfield and Suizhong 36-1 oilfield central platform are classified as serious pollution and light pollution respectively, which is consistent with relevant institutions and scholars, proving the rationality of the evaluation system and parameter selected.
\end{abstract}

\section{Introduction}

In recent years, there have been several oil spill accidents in the Bohai Sea [1-5]. Oil spills into seawater, then drifts and diffuses under the influence of environmental dynamic fields, which causes pollution to the marine [610]. There are some differences among pollution degree of oil spill accidents to some extent [11-13]. Evaluation on pollution degree affects emergency response, hazard assessment and loss compensation [14]. Therefore, classification of pollution degree of oil spills on the sea surface is of significance to determine the corresponding emergency and respond to oil spill hazards efficiently and scientifically [15].

This paper applies a multi-level fuzzy comprehensive evaluation method to establishing pollution evaluation system of oil spills on the sea surface in section Evaluation System of Oil Spill Pollution. Section Membership of Evaluation Indexes elaborates membership degree of each evaluation index. Analytic hierarchy process is used to determine weight of each index in Section Weights of Evaluation Indexes. Pollution degree of oil spills on the sea surface is evaluated in Section Multi-level Fuzzy Comprehensive Evaluation and pollution degree of oil spill accidents in Penglai 19-3 oilfield and in Suizhong 36-1 oilfield is analysed in Section Case Analysis of Oil Spills on the Sea Surface.

\section{Evaluation System of Oil Spill Pollution}

At present, various methods [16-18] are widely used to evaluate pollution degree of oil spills on the sea surface, comprehensive evaluation method is adopted in the paper since it takes multiple effects of indicators into account synthetically [19].

Pollution degree of oil spills on the sea surface is related to factors as oil properties, spill location, meteorological and hydrological conditions as well as emergency measures [20]. Due to uncertainties and interaction in these factors, there is some ambiguity in evaluating pollution level [21], thus Fuzzy Comprehensive Evaluation (FCE) [22] is applied.

According to data source in weight calculation, methods to determine weights of indexes can be divided into subjective weighting method and objective method [23]. Subjective weighting methods include expert survey method (Delphi method) [24] and analytic hierarchy process (AHP) [25-26]. Objective weighting methods include principal component analysis [27], entropy method [28] and multi-objective programming method [29].

AHP this paper selected suits decision-making problems where evaluation indicators are complicatedly layered and the target values are difficult to describe quantitatively. The advantage of AHP lies in clear and systematic procedures as well as less data during analysis.

The main influence factors are determined and evaluation system of pollution degree of oil spills on the sea surface is established [30].

According to the evaluation system, there are 6 firstlevel evaluation factor sets and 23 second-level evaluation factor sets, first-level evaluation factor set represent as $\mathrm{U}=$ \{oil spill amount $\mathrm{U}_{1}$, oil properties $\mathrm{U}_{2}$, oil spill position $\mathrm{U}_{3}$, meteorological factors $\mathrm{U}_{4}$, hydrological factors $\mathrm{U}_{5}$, emergency measures $\left.\mathrm{U}_{6}\right\}$, second-level evaluation factor sets are $\mathrm{U}_{2}=$ \{toxicity $\mathrm{U}_{21}$, persistence $\mathrm{U}_{22}$, flammability $U_{23}$, viscosity $\left.U_{24}\right\}, U_{3}=\left\{\right.$ marine sensitive resources $U_{31}$, offshore distance $\mathrm{U}_{32}$, shoreline type $\left.\mathrm{U}_{33}\right\}, \mathrm{U}_{4}=\{$ wind

\footnotetext{
*Corresponding author: zhouxupc@163.com
} 
speed $\mathrm{U}_{41}$, wind direction $\mathrm{U}_{42}$, visibility $\left.\mathrm{U}_{43}\right\}$, $\mathrm{U}_{5}=$ \{current velocity $\mathrm{U}_{51}$, current direction $\mathrm{U}_{52}$, water temperature $\mathrm{U}_{53}$, wave height $\left.\mathrm{U}_{54}\right\}, \mathrm{U}_{6}=\{$ risk identification and control capabilities $U_{61}$, emergency resource support capabilities $\mathrm{U}_{62}$, emergency processing capabilities $U_{63}$, emergency plan preparation capabilities $\mathrm{U}_{64}$, emergency recovery capabilities $\left.\mathrm{U}_{65}\right\}$.

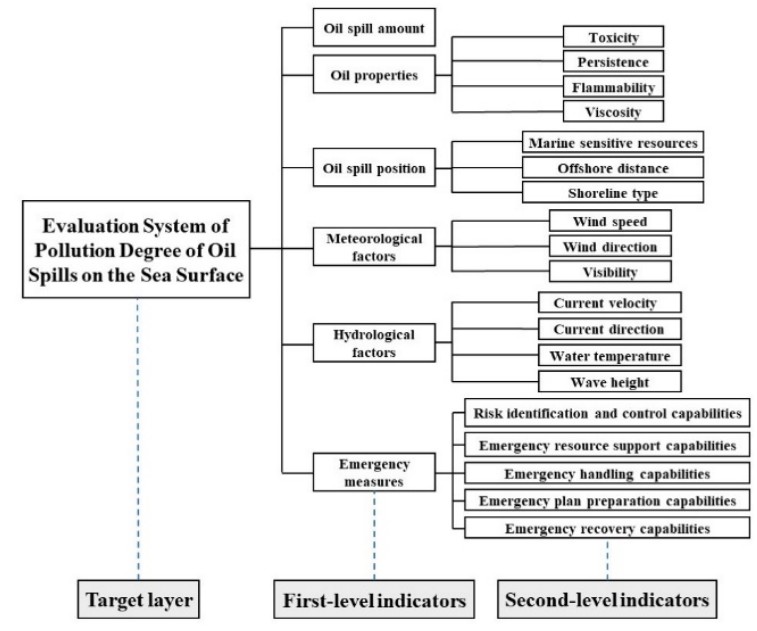

Figure 1. Evaluation system of pollution degree of oil spills on the sea surface

Pollution degree is divided into five levels and comment set is expressed as $\mathrm{V}=\left\{\mathrm{V}_{1}, \mathrm{~V}_{2}, \mathrm{~V}_{3}, \mathrm{~V}_{4}, \mathrm{~V}_{5}\right\}$ in which $V_{j}(j=1,2, \ldots, 5)$ represents five pollution levels, namely extremely light, light, medium, heavy and serious pollution respectively.

\section{Membership of Evaluation Indexes}

Membership of evaluation indexes [31] is quantitative description of comment set on factor set and normally determined by membership function or subset table of membership [32]. Among them, membership of subindicators such as oil spills, marine sensitivity and offshore distance is determined by establishing membership function curve and membership of other indexes is determined by constructing membership subset table.

\subsection{Membership function of oil spill amount}

Combining decree No.15 of the Ministry of Transport of the people's Republic of China on statistical measures for water traffic accidents (2014) with British method of dividing points for oil spill evaluation, a triangular and trapezoidal method is applied to determining membership function of oil spill amount.

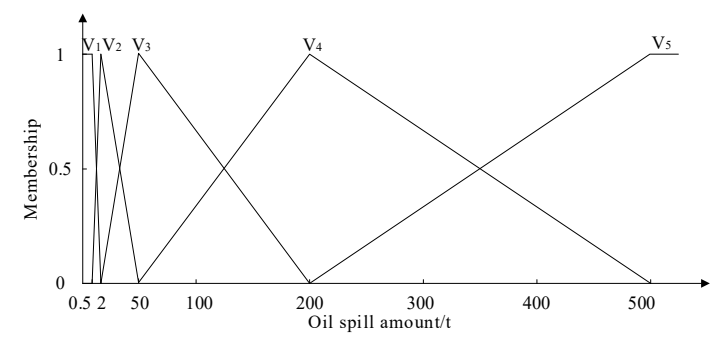

Figure 2. Membership function of oil spill amount

For example, membership function of oil spill amount $\mathrm{t}$ for extremely light pollution $\mathrm{V}_{1}$ is

$$
V_{1(t)}=\left\{\begin{array}{lc}
1 & t \leq 0.5 \\
1-(t-0.5) / 1.5 & 0.5<t \leq 2 \\
0 & t>2
\end{array}\right.
$$

\subsection{Subset table of sub-indexes of oil properties}

Membership of oil properties as toxicity, persistence, flammability and viscosity are invested [33]. Toxicity of crude oil depends on its composition, corresponding proportion, physical and chemical properties of each composition [34]. According to hydrocarbon compounds, crude oil can be divided into paraffins, paraffins and naphthenes, naphthenes, naphthenes and aromatic hydrocarbons as well as aromatic hydrocarbons.

Persistence refers to the ability to remain in the water without being degraded [35]. In general, the greater density of oil spills, the stronger persistence and the longer retention time, the more serious damage to the marine. According to $\mathrm{API}^{\circ}$, crude oil can be divided into light $(>34)$, medium (20 34), heavy (10 20) and extra thick crude oil $(<10)$.

Flammability of oil spills brings potential danger to emergency operation and it depends on flash point of oil spills [36]. The lower the flash point, the more dangerous of oil spills. Accordingly, oil products can be divided into lubricating oil and grease $\left(>125^{\circ} \mathrm{C}\right)$, diesel and heavy oil $\left(45 \sim 125^{\circ} \mathrm{C}\right)$, kerosene $\left(28 \sim 45{ }^{\circ} \mathrm{C}\right)$, solvent oil and gasoline $\left(<28^{\circ} \mathrm{C}\right)$.

Viscosity represents fluidity of oil spills. The greater the viscosity, the higher the membership value assigned to a higher pollution level [37]. On account of viscosity, crude oil can be divided into conventional oil $(<100$ $\mathrm{mPa} \cdot \mathrm{s})$, heavy oil $(100 \sim 10000 \mathrm{mPa} \cdot \mathrm{s})$, extra heavy oil $(10000 \sim 50000 \mathrm{mPa} \cdot \mathrm{s})$ and super heavy oil $(>50000$ $\mathrm{mPa} \cdot \mathrm{s})$.

Table1. Membership subset of sub-indexes of oil properties

\begin{tabular}{|c|c|c|c|c|c|c|c|}
\hline \multirow{2}{*}{$\begin{array}{l}\text { Sub-indexes } \\
\text { of Oil } \\
\text { properties }\end{array}$} & \multirow{2}{*}{ Weight } & \multirow{2}{*}{ Level } & \multicolumn{5}{|c|}{ Comment Set } \\
\hline & & & $\mathrm{V}_{1}$ & $\mathrm{~V}_{2}$ & $\mathrm{~V}_{3}$ & $\mathrm{~V}_{4}$ & $\mathrm{~V}_{5}$ \\
\hline \multirow{5}{*}{ Toxicity } & \multirow{5}{*}{0.4782} & 1 & 0.8 & 0.2 & 0 & 0 & 0 \\
\hline & & 2 & 0.2 & 0.6 & 0.2 & 0 & 0 \\
\hline & & 3 & 0 & 0.2 & 0.6 & 0.2 & 0 \\
\hline & & 4 & 0 & 0 & 0.1 & 0.6 & 0.3 \\
\hline & & 5 & 0 & 0 & 0 & 0.2 & 0.8 \\
\hline
\end{tabular}




\begin{tabular}{|c|c|c|c|c|c|c|c|}
\hline \multirow{4}{*}{ Persistence } & \multirow{4}{*}{0.1817} & 1 & 0.8 & 0.2 & 0 & 0 & 0 \\
\hline & & 2 & 0.2 & 0.6 & 0.2 & 0 & 0 \\
\hline & & 3 & 0 & 0.2 & 0.6 & 0.2 & 0 \\
\hline & & 4 & 0 & 0 & 0 & 0.2 & 0.8 \\
\hline \multirow{4}{*}{ Flammability } & \multirow{4}{*}{0.2321} & 1 & 0.8 & 0.2 & 0 & 0 & 0 \\
\hline & & 2 & 0.2 & 0.6 & 0.2 & 0 & 0 \\
\hline & & 3 & 0 & 0.2 & 0.6 & 0.2 & 0 \\
\hline & & 4 & 0 & 0 & 0 & 0.2 & 0.8 \\
\hline \multirow{4}{*}{ Viscosity } & \multirow{4}{*}{0.1080} & 1 & 0.8 & 0.2 & 0 & 0 & 0 \\
\hline & & 2 & 0.2 & 0.6 & 0.2 & 0 & 0 \\
\hline & & 3 & 0 & 0.2 & 0.6 & 0.2 & 0 \\
\hline & & 4 & 0 & 0 & 0 & 0.2 & 0.8 \\
\hline
\end{tabular}

\subsection{Subset table of indexes of oil spill location}

Oil spill areas can be divided into sensitive and nonsensitive areas [38]. The richer the sensitive resources near the spill location, the more serious the pollution will be [39]. Once sensitive area is polluted, oil will cause heavy losses and huge ecological disasters [40].

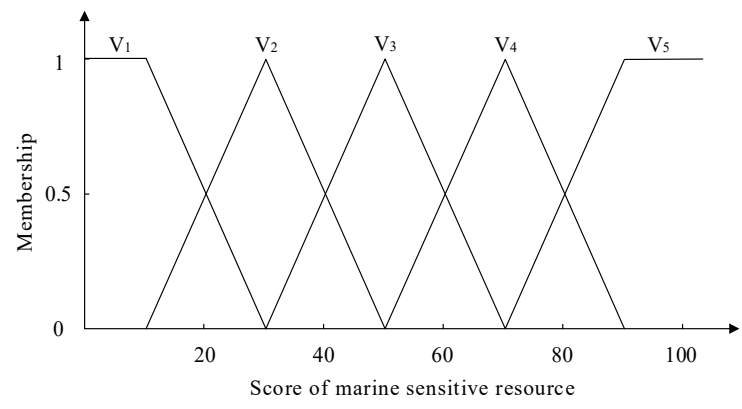

Figure 3. Membership function of marine sensitive resources

Take membership function of score $\mathrm{x}$ of sensitive resources for extremely light pollution $\mathrm{V}_{1}$ as an example

$$
V_{1}(x)=\left\{\begin{array}{lc}
1 & x \leq 10 \\
1.5-x / 20 & 10<x \leq 30 \\
0 & x>30
\end{array}\right.
$$

The closer the spill location to shore, the higher the pollution degree [41]. Function curve of membership of offshore distance is illustrated.

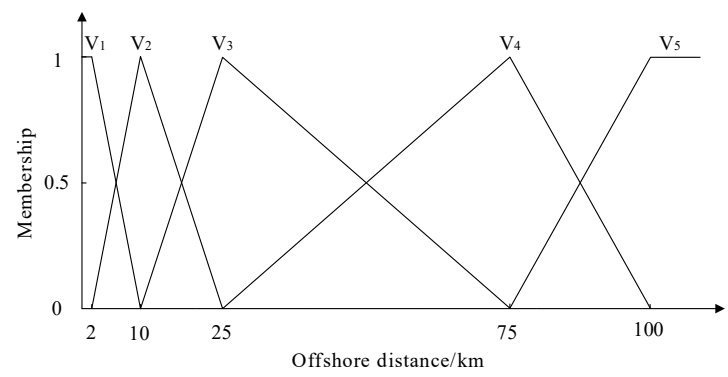

Figure 4. Membership function of offshore distance
For example, membership function of offshore distance $\mathrm{d}$ for extreme light pollution $\mathrm{V}_{1}$ is

$$
V_{1}(d)=\left\{\begin{array}{lc}
0 & d \leq 75 \\
(d-75) / 25 & 75<d \leq 100 \\
1 & d>100
\end{array}\right.
$$

With reference to Environmental Sensitivity Index (ESI) [42-43], coastlines can be divided into bedrock coast, gravel coast, plain coast, mangrove coast and coral reef coast in China and the membership subset is shown.

Table2. Membership subset of coastline types

\begin{tabular}{cccccc}
\hline Shoreline & $\mathrm{V}_{1}$ & $\mathrm{~V}_{2}$ & $\mathrm{~V}_{3}$ & $\mathrm{~V}_{4}$ & $\mathrm{~V}_{5}$ \\
\hline 1 & 0.8 & 0.2 & 0 & 0 & 0 \\
2 & 0.2 & 0.6 & 0.2 & 0 & 0 \\
3 & 0 & 0.2 & 0.6 & 0.2 & 0 \\
4 & 0 & 0 & 0.2 & 0.6 & 0.2 \\
5 & 0 & 0 & 0 & 0.1 & 0.9 \\
\hline
\end{tabular}

\subsection{Subset table of indexes of meteorological factors}

Meteorological factors such as wind speed, wind direction and visibility influence pollution degree of oil spills on the sea surface [44].

Wind speed [45] determines wave size to some extent, promotes dispersion of oil spills, expands pollution area and adversely affects the recovery and treatment of oil spills, resulting in increased pollution level. According to wind speed, wind levels can be divided into level $1(<1.5$ $\mathrm{m} / \mathrm{s})$, level $2(1.5 \sim 5.4 \mathrm{~m} / \mathrm{s})$, level $3(5.4 \sim 10.7 \mathrm{~m} / \mathrm{s})$, level 4 $(10.7 \sim 20.7 \mathrm{~m} / \mathrm{s})$ and level $5(>20.7 \mathrm{~m} / \mathrm{s})$.

Wind direction [46] affects drift trajectory and diffusion direction of oil spills, and may cause serious pollution to coastal sensitive areas. According to the angle between wind direction and coastal sensitive area, wind direction is divided into three levels: reverse coastal sensitive area, a certain angle with coastal sensitive area and forward sensitive coastal area.

Visibility reflects atmosphere's transparency [47], which impacts satellite monitoring and emergency treatment, thus increasing pollution degree of oil spills. With reference to Horizontal Visibility Level, visibility at the sea surface is divided into level 1 (>4000 m), level 2 (1000 4000 m), level 3 (200 1000 m), level 4 (100 200 $\mathrm{m})$ and level $5(<100 \mathrm{~m})$.

Table3. Membership subset of sub-indexes of

\begin{tabular}{|c|c|c|c|c|c|c|c|}
\hline \multirow{2}{*}{$\begin{array}{l}\text { Sub-indexes of } \\
\text { Meteorological } \\
\text { Factors }\end{array}$} & \multirow{2}{*}{ Weight } & \multirow{2}{*}{ Level } & \multicolumn{5}{|c|}{ Comment Set } \\
\hline & & & $\mathrm{V}_{1}$ & $\mathrm{~V}_{2}$ & $\mathrm{~V}_{3}$ & $\mathrm{~V}_{4}$ & $\mathrm{~V}_{5}$ \\
\hline \multirow{7}{*}{ Wind speed } & \multirow{5}{*}{0.5278} & 1 & 0.8 & 0.2 & 0 & 0 & 0 \\
\hline & & 2 & 0.2 & 0.6 & 0.2 & 0 & 0 \\
\hline & & 3 & 0 & 0.2 & 0.6 & 0.2 & 0 \\
\hline & & 4 & 0 & 0 & 0.1 & 0.6 & 0.3 \\
\hline & & 5 & 0 & 0 & 0 & 0.1 & 0.9 \\
\hline & & 1 & 0.8 & 0.2 & 0 & 0 & 0 \\
\hline & & 2 & 0 & 0.1 & 0.6 & 0.3 & 0 \\
\hline
\end{tabular}
meteorological factors 


\begin{tabular}{c|c|c|c|c|c|c|c}
\hline & & 3 & 0 & 0 & 0 & 0.1 & 0.9 \\
\hline \multirow{4}{*}{ Visibility } & & 1 & 0.8 & 0.2 & 0 & 0 & 0 \\
\cline { 3 - 8 } & & 2 & 0.2 & 0.6 & 0.2 & 0 & 0 \\
\cline { 3 - 8 } & 0.1396 & 3 & 0 & 0.2 & 0.6 & 0.2 & 0 \\
\cline { 3 - 8 } & 4 & 0 & 0 & 0.2 & 0.7 & 0.1 \\
\hline & & 5 & 0 & 0 & 0 & 0.1 & 0.9 \\
\hline
\end{tabular}

\subsection{Subset table of hydrological factors}

Hydrological factors as current velocity, current direction, water temperature and wave height affect pollution degree of oil spills on the sea surface [48].

Current velocity [49] increases oil diffusion and is not conducive to oil spill recovery, which aggravates oil spill pollution, and it can be divided into level $1(<0.5 \mathrm{~m} / \mathrm{s})$, level $2(0.5 \sim 1 \mathrm{~m} / \mathrm{s})$, level $3(1 \sim 1.5 \mathrm{~m} / \mathrm{s})$, level $4(1.5 \sim 2 \mathrm{~m} / \mathrm{s})$ and level $5(>2 \mathrm{~m} / \mathrm{s})$.

Current direction and wind direction jointly determine drift direction of oil spills. Drifting to coastal sensitive resources may cause more serious harm to coastal ecological environment. According to the angle between current direction and coastal sensitive area, current direction is divided into 3 levels: reverse, at an angle and forward.

Water temperature [50] in the sea surface directly affects evaporation of oil spills. Volatilization of light components alters oil properties, which has a certain impact on other weathering processes. In addition, evaporation leads to a reduction in oil spill volume, thereby reducing its pollution degree. Water temperature can be divided into level $1\left(>25^{\circ} \mathrm{C}\right)$, level $2\left(20 \sim 25^{\circ} \mathrm{C}\right)$, level $3\left(15 \sim 20{ }^{\circ} \mathrm{C}\right)$, level $4\left(10 \sim 15{ }^{\circ} \mathrm{C}\right)$ and level 5 ($\left.5 \sim 10{ }^{\circ} \mathrm{C}\right)$.

Wave disturbance [51] promotes stirring of oil spills and water, accelerates formation of emulsions and some oil break into small liquid clumps or droplets, increasing the difficulty of oil spill recovery. Wave disturbance is measured by wave height which can be divided into level $1(<0.5 \mathrm{~m})$, level $2(0.5 \sim 1.5 \mathrm{~m})$, level $3(1.5 \sim 3 \mathrm{~m})$, level 4 (3 9 $\mathrm{m})$ and level $5(>9 \mathrm{~m})$.

Table4. Membership subset of sub-index of hydrological factors

\begin{tabular}{|c|c|c|c|c|c|c|c|}
\hline \multirow{2}{*}{$\begin{array}{l}\text { Sub-indexes } \\
\text { of } \\
\text { Hydrological }\end{array}$} & \multirow{2}{*}{ Weight } & \multirow{2}{*}{ Level } & \multicolumn{5}{|c|}{ Comment Set } \\
\hline & & & $\mathrm{V}_{1}$ & $\mathrm{~V}_{2}$ & $\mathrm{~V}_{3}$ & $\mathrm{~V}_{4}$ & $\mathrm{~V}_{5}$ \\
\hline \multirow{5}{*}{ Current } & \multirow{5}{*}{0.420303} & 1 & 0.8 & 0.2 & 0 & 0 & 0 \\
\hline & & 2 & 0.2 & 0.6 & 0.2 & 0 & 0 \\
\hline & & 3 & 0 & 0.2 & 0.6 & 0.2 & 0 \\
\hline & & 4 & 0 & 0 & 0.2 & 0.6 & 0.2 \\
\hline & & 5 & 0 & 0 & 0 & 0.1 & 0.9 \\
\hline \multirow{7}{*}{$\begin{array}{l}\text { Current } \\
\text { direction }\end{array}$} & \multirow{3}{*}{0.1899} & 1 & 0.8 & 0.2 & 0 & 0 & 0 \\
\hline & & 2 & 0 & 0.2 & 0.6 & 0.2 & 0 \\
\hline & & 3 & 0 & 0 & 0 & 0.1 & 0.9 \\
\hline & & 1 & 0.8 & 0.2 & 0 & 0 & 0 \\
\hline & & 2 & 0.2 & 0.6 & 0.2 & 0 & 0 \\
\hline & & 3 & 0 & 0.2 & 0.6 & 0.2 & 0 \\
\hline & & 4 & 0 & 0 & 0.2 & 0.6 & 0.2 \\
\hline
\end{tabular}

\begin{tabular}{c|c|c|c|c|c|c|c}
\hline & & 5 & 0 & 0 & 0 & 0.2 & 0.8 \\
\hline \multirow{4}{*}{ Wave height } & \multirow{4}{*}{0.2685} & 1 & 0.8 & 0.2 & 0 & 0 & 0 \\
\cline { 4 - 9 } & 2 & 0.2 & 0.6 & 0.2 & 0 & 0 \\
\cline { 3 - 9 } & & 3 & 0 & 0.2 & 0.6 & 0.2 & 0 \\
\cline { 3 - 9 } & & 4 & 0 & 0 & 0.2 & 0.6 & 0.2 \\
\cline { 3 - 9 } & & 5 & 0 & 0 & 0 & 0.2 & 0.8 \\
\hline
\end{tabular}

\subsection{Subset table of emergency measures}

Emergency measures play an important role in controlling oil spills and reducing pollution [52]. Sub-indexes of emergency measures mainly include qualitative indicators such as risk identification and control capabilities, emergency resource support capabilities, emergency handling capabilities, emergency plan preparation capabilities and emergency recovery capabilities. Evaluation degree of emergency measures can be classified into excellent, good, medium, passing and poor. With reference to regulations as IMO's Manual on oil spill risk evaluation and assessment of response preparedness, Marine Environment Protection Law of the People's Republic of China and National Environmental Emergency Plan announced by General Office of the State Council as well as experienced scholars [53], membership subset for sub-indicators of emergency measures is shown.

Table5. Membership subset of sub-indexes of emergency measures

\begin{tabular}{|c|c|c|c|c|c|c|c|}
\hline \multirow{2}{*}{$\begin{array}{c}\text { Sub-indexes } \\
\text { of } \\
\text { Emergency }\end{array}$} & \multirow{2}{*}{ Weight } & \multirow{2}{*}{ Level } & \multicolumn{5}{|c|}{ Comment Set } \\
\hline & & & $\mathrm{V}_{1}$ & $\mathrm{~V}_{2}$ & $\mathrm{~V}_{3}$ & $\mathrm{~V}_{4}$ & $\mathrm{~V}_{5}$ \\
\hline \multirow{5}{*}{$\begin{array}{c}\text { Risk } \\
\text { identification } \\
\text { and control } \\
\text { capabilities }\end{array}$} & \multirow{5}{*}{0.2157} & 1 & 0.8 & 0.2 & 0 & 0 & 0 \\
\hline & & 2 & 0.2 & 0.6 & 0.2 & 0 & 0 \\
\hline & & 3 & 0 & 0.2 & 0.6 & 0.2 & 0 \\
\hline & & 4 & 0 & 0 & 0.1 & 0.6 & 0.3 \\
\hline & & 5 & 0 & 0 & 0 & 0.1 & 0.9 \\
\hline \multirow{5}{*}{$\begin{array}{l}\text { Emergency } \\
\text { resource } \\
\text { support } \\
\text { capabilities }\end{array}$} & \multirow{5}{*}{0.2325} & 1 & 0.8 & 0.2 & 0 & 0 & 0 \\
\hline & & 2 & 0.2 & 0.6 & 0.2 & 0 & 0 \\
\hline & & 3 & 0 & 0.2 & 0.6 & 0.2 & 0 \\
\hline & & 4 & 0 & 0 & 0.1 & 0.6 & 0.3 \\
\hline & & 5 & 0 & 0 & 0 & 0.1 & 0.9 \\
\hline \multirow{5}{*}{$\begin{array}{l}\text { Emergency } \\
\text { handling } \\
\text { capabilities }\end{array}$} & \multirow{5}{*}{0.3601} & 1 & 0.9 & 0.1 & 0 & 0 & 0 \\
\hline & & 2 & 0.1 & 0.6 & 0.3 & 0 & 0 \\
\hline & & 3 & 0 & 0.1 & 0.6 & 0.3 & 0 \\
\hline & & 4 & 0 & 0 & 0.1 & 0.6 & 0.3 \\
\hline & & 5 & 0 & 0 & 0 & 0.1 & 0.9 \\
\hline \multirow{5}{*}{$\begin{array}{c}\text { Emergency } \\
\text { plan } \\
\text { preparation } \\
\text { capabilities }\end{array}$} & \multirow{5}{*}{0.1918} & 1 & 0.8 & 0.2 & 0 & 0 & 0 \\
\hline & & 2 & 0.2 & 0.6 & 0.2 & 0 & 0 \\
\hline & & 3 & 0 & 0.2 & 0.6 & 0.2 & 0 \\
\hline & & 4 & 0 & 0 & 0.2 & 0.6 & 0.2 \\
\hline & & 5 & 0 & 0 & 0 & 0.2 & 0.8 \\
\hline \multirow{5}{*}{$\begin{array}{c}\text { Emergency } \\
\text { recovery } \\
\text { capabilities }\end{array}$} & \multirow{5}{*}{0.2809} & 1 & 0.8 & 0.2 & 0 & 0 & 0 \\
\hline & & 2 & 0.2 & 0.6 & 0.2 & 0 & 0 \\
\hline & & 3 & 0 & 0.2 & 0.6 & 0.2 & 0 \\
\hline & & 4 & 0 & 0 & 0.2 & 0.6 & 0.2 \\
\hline & & 5 & 0 & 0 & 0 & 0.2 & 0.8 \\
\hline
\end{tabular}




\section{Membership of Evaluation Indexes}

AHP is used to determine the weight of each index [54] and weights of oil properties and oil spill position are present respectively.

Table6. Weight of sub-indexes of oil properties

\begin{tabular}{cccccc}
\hline $\begin{array}{c}\text { Oil } \\
\text { Properties } \\
\mathrm{U}_{2}\end{array}$ & $\begin{array}{c}\text { Toxicit } \\
\mathrm{y} \mathrm{U}_{21}\end{array}$ & $\begin{array}{c}\text { Persiste } \\
\text { nce } \mathrm{U}_{22}\end{array}$ & $\begin{array}{c}\text { Flammabi } \\
\text { lity } \mathrm{U}_{23}\end{array}$ & $\begin{array}{c}\text { Visco } \\
\text { sity } \\
\mathrm{U}_{24}\end{array}$ & Weight \\
\hline $\begin{array}{c}\text { Toxicity } \\
\mathrm{U}_{21}\end{array}$ & 1 & 2 & 3 & 4 & 0.4782 \\
$\begin{array}{c}\text { Persistenc } \\
\text { e } \mathrm{U}_{22}\end{array}$ & $1 / 2$ & 1 & $1 / 2$ & 2 & 0.1817 \\
$\begin{array}{c}\text { Flammabil } \\
\text { ity } \mathrm{U}_{23}\end{array}$ & $1 / 3$ & 2 & 1 & 2 & 0.2321 \\
$\begin{array}{c}\text { Viscosity } \\
\mathrm{U}_{24}\end{array}$ & $1 / 4$ & $1 / 2$ & $1 / 2$ & 1 & 0.1080 \\
\hline
\end{tabular}

Table7. Weight of sub-indexes of oil spill location

\begin{tabular}{ccccc}
\hline $\begin{array}{c}\text { Oil Spill } \\
\text { Location } U_{3}\end{array}$ & $\begin{array}{c}\text { Marine } \\
\text { sensitive } \\
\text { Resources } \\
\mathrm{U}_{31}\end{array}$ & $\begin{array}{c}\text { Offshore } \\
\text { distance } \\
\mathrm{U}_{32}\end{array}$ & $\begin{array}{c}\text { Shoreline } \\
\text { type } \mathrm{U}_{33}\end{array}$ & Weight \\
\hline $\begin{array}{c}\text { Marine } \\
\text { sensitive }\end{array}$ & 1 & 2 & 3 & 0.5499 \\
$\begin{array}{c}\text { resources } \mathrm{U}_{31} \\
\text { Offshore } \\
\text { distance } \mathrm{U}_{32}\end{array}$ & $1 / 2$ & 1 & 1 & 0.2402 \\
$\begin{array}{c}\text { Shoreline } \\
\text { type U33 }\end{array}$ & $1 / 2$ & 1 & 1 & 0.2098 \\
\hline
\end{tabular}

Table8. Weight of evaluation indexes of oil spill pollution degree

\begin{tabular}{cccccccc}
\hline Indexes & $\mathrm{U}_{1}$ & $\mathrm{U}_{2}$ & $\mathrm{U}_{3}$ & $\mathrm{U}_{4}$ & $\mathrm{U}_{5}$ & $\mathrm{U}_{6}$ & Weight \\
\hline $\mathrm{U}_{1}$ & 1 & 2 & $3 / 2$ & $6 / 5$ & $6 / 5$ & $3 / 4$ & 0.2013 \\
$\mathrm{U}_{2}$ & $1 / 2$ & 1 & $5 / 6$ & $3 / 4$ & $3 / 4$ & $2 / 3$ & 0.1098 \\
$\mathrm{U}_{3}$ & $2 / 3$ & $6 / 5$ & 1 & $3 / 4$ & $3 / 4$ & $5 / 6$ & 0.1308 \\
$\mathrm{U}_{4}$ & $6 / 5$ & $4 / 3$ & $4 / 3$ & 1 & $6 / 5$ & $5 / 6$ & 0.1722 \\
$\mathrm{U}_{5}$ & $5 / 6$ & $4 / 3$ & $4 / 3$ & $5 / 6$ & 1 & $5 / 6$ & 0.1601 \\
$\mathrm{U}_{6}$ & $4 / 3$ & $3 / 2$ & 2 & $6 / 5$ & $6 / 5$ & 1 & 0.2259 \\
\hline
\end{tabular}

Since the consistency ratio CR [55-56] is less than 0.1 for the weight of each index, according judgment matrix has good consistency, that is, the weight distribution is reasonable.

\section{Multi-level Fuzzy Comprehensive Evaluation}

In the fuzzy comprehensive evaluation, $\circ$ represents a fuzzy matrix synthesis operator in $B=A \circ R$ [57]. This paper selects a weighted average operator [58-59], which indicates all factors are balanced according to the weight and it is applicable to the effect of various factors.

Evaluation system for pollution degree of oil spills on the sea surface is a second-level fuzzy evaluation. Taking oil properties as an example to illustrate the process of the first-level fuzzy comprehensive evaluation, the membership matrix $\mathrm{R}_{2}$ can be obtained from the subset table of toxicity, persistence, flammability and viscosity.

$$
R_{2}=\left[\begin{array}{lllll}
r_{11}^{2} & r_{12}^{2} & r_{13}^{2} & r_{14}^{2} & r_{15}^{2} \\
r_{21}^{2} & r_{22}^{2} & r_{23}^{2} & r_{24}^{2} & r_{25}^{2} \\
r_{31}^{2} & r_{32}^{2} & r_{33}^{2} & r_{34}^{2} & r_{35}^{2} \\
r_{41}^{2} & r_{42}^{2} & r_{43}^{2} & r_{44}^{2} & r_{45}^{2}
\end{array}\right]
$$

$\mathrm{A}_{2}=\left(\mathrm{A}_{21}, \mathrm{~A}_{22}, \mathrm{~A}_{23}, \mathrm{~A}_{24}\right)$ represents the weight set of sub-indexes and the result matrix of fuzzy comprehensive evaluation $\mathrm{B}_{2}$ for oil property $\mathrm{U}_{2}$ is

$$
\begin{gathered}
B_{2}=A_{2} \circ R_{2}=\left(b_{21}, b_{22}, b_{23}, b_{24}, b_{25}\right)=\left(A_{21}, A_{22}, A_{23}, A_{24}\right) \circ \\
{\left[\begin{array}{ccccc}
r_{11}^{2} & r_{12}^{2} & r_{13}^{2} & r_{14}^{2} & r_{15}^{2} \\
r_{21}^{2} & r_{22}^{2} & r_{23}^{2} & r_{24}^{2} & r_{25}^{2} \\
r_{31}^{2} & r_{32}^{2} & r_{33}^{2} & r_{34}^{2} & r_{35}^{2} \\
r_{41}^{2} & r_{42}^{2} & r_{43}^{2} & r_{44}^{2} & r_{45}^{2}
\end{array}\right]}
\end{gathered}
$$

Therefore, the total evaluation matrix R of the fuzzy comprehensive evaluation system can be obtained as

$$
R=\left[\begin{array}{l}
B_{1} \\
B_{2} \\
B_{3} \\
B_{4} \\
B_{5} \\
B_{6}
\end{array}\right]=\left[\begin{array}{l}
A_{1} \circ R_{1} \\
A_{2} \circ R_{2} \\
A_{3} \circ R_{3} \\
A_{4} \circ R_{4} \\
A_{5} \circ R_{5} \\
A_{6} \circ R_{6}
\end{array}\right]
$$

The second-level fuzzy comprehensive evaluation result is $B=A \circ R$, which is the overall evaluation result of pollution degree of oil spills on the sea surface, where $\mathrm{A}$ is the weight of the first-level indexes.

\section{Case Analysis of Oil Spills on the Sea Surface}

\subsection{Pollution evaluation of oil spill in Penglai 19- 3 oilfield}

In Penglai 19-3 oilfield, there were two oil spill accidents on June 4 and 17 in 2011 when was off-season in the Bohai Sea and oil spill amount was at least 940 t [60-61]. The location is about $70 \mathrm{~km}$ from the nearest coast Longkou coast and the shoreline is sandy type. Coastal sensitive resources include nature reserves, marine special protection areas, natural landscapes, historical and cultural heritage areas, fishery waters, coastal tourist areas, port shipping areas and special utilization areas in adjacent marine. State Oceanography Bureau implemented three-dimensional all-weather surveillance and monitoring on the oil spill accident the first time. However, due to the deliberate delay of the responsible party for the accident, ConocoPhillips did not fully control the spill situation, the progress of oil spill investigation and plugging was slow, oil spills in platform $\mathrm{B}$ and $\mathrm{C}$ was basically controlled until June 19 and June 21 respectively.

At the time of oil spill accident, wind on the sea surface was about $5.7 \mathrm{~m} / \mathrm{s}$ and there was a certain angle between wind direction and coastal sensitive resources. Current velocity was approximately $0.5 \sim 1 \mathrm{~m} / \mathrm{s}$ and it was directly opposite coastal sensitive resources, wave height 
was less than $1 \mathrm{~m}$. The spilled oil is medium or heavy, mainly isoparaffin or cycloalkane but less n-paraffin, with low alkane content $(32.8 \% \sim 44.6 \%)$ and higher colloid content $(18.9 \% \sim 29.8 \%)$. API of ground crude oil is about 17.4 , closed flash point is about $40^{\circ} \mathrm{C}$ (open flash point is $\left.75^{\circ} \mathrm{C}\right)$, and its viscosity is about $60.42 \sim 3957 \mathrm{~Pa} \cdot \mathrm{s}\left(50^{\circ} \mathrm{C}\right)$.

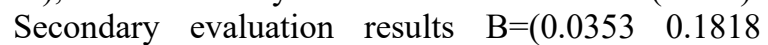
0.23580 .11360 .4375 ), according to the principle of maximum membership, Penglai 19-3 oil spill accident belongs to serious pollution, which is consistent with the result of Emergency Oil Exploration and Development Oil Spill Emergency Plan issued by State Oceanography Bureau on April 3rd, 2015.

\subsection{Pollution evaluation of oil spill in Suizhong 36-1 oilfield}

On November 26, 2002, an oil spill accident occurred on the central platform of Suizhong 36-1 oilfield in the Bohai Sea [62]. Referring to the method of determining the membership degree of emergency measures taken by Zhang Qian [63], this paper considers the emergency measures on the oil spill accident at a good level. Adopting the relevant data by Liu Jie [64], the secondlevel fuzzy comprehensive evaluation method is applied to evaluating the pollution degree of the oil spill and the total evaluation matrix is obtained as $\mathrm{B}=(0.20430 .6071$ $0.20070 .04760 .0039)$. According to the principle of maximum membership, oil spill accident on the central platform of Suizhong 36-1 oilfield is classified as light pollution, which is consistent with the conclusion drawn by Liu Jie [64].

\section{Conclusion}

In this paper, multi-level fuzzy comprehensive evaluation method is applied to establishing pollution evaluation system for oil spills on the sea surface and analytic hierarchy process combining qualitative and quantitative analysis is applied to determining weights of each index.

(1) Evaluation system of oil spill pollution on the sea surface is established by multi-level fuzzy comprehensive evaluation method. There are 6 first-level evaluation factor sets and 23 second-level evaluation factor sets. Pollution degree of oil spills is divided into 5 levels, which are respectively extremely light, light, medium, heavy and serious pollution.

(2) Membership degree of sub-indexes such as oil spill amount, marine sensitive resources and offshore distance is determined by establishing membership function, while membership degree of other indexes is determined by constructing membership subset table.

(3) Analytic hierarchy process is applied to determining weight of each sub-index and the fuzzy operator in the multi-level fuzzy comprehensive evaluation is determined by a weighted average model, thus the sub-indexes can be balanced and considered in accordance with the corresponding weight.

(4) Based on the principle of maximum membership, oil spill accidents in Penglai 19-3 oilfield and in the central platform of Suizhong 36-1 oilfield are evaluated as serious pollution and light pollution respectively, which signifies feasibility and rationality of the evaluation system of pollution degree of oil spills on the sea surface.

\section{References}

1. Sun P Y, Gao Z H, Zhou Q, et al. Evaluation of the Oil Spill Accident in Bohai Sea, China[J]. Environ. Forensics,2009,10(4):308-316.

2. Van-Cuong Do, Hong-Xiang Ren. Simulation of Bohai sea tidal during Penglai 19-3 oil spill accident based on Mike21 model[C]. 2019 2nd Asia Conference on Energy and Environment Engineering (ACEEE),2019.

3. Jie G, Xin L, Qiang X .Characteristics of the Bohai Sea oil spill and its impact on the Bohai Sea ecosystem[J]. Chinese Science Bulletin, 2013, 58(019):2276-2281.

4. Li H , Li Y, Li C, et al. Bohai and Yellow Sea Oil Spill Prediction System and Its Application to Huangdao '11.22' Oil Spill Incident[J]. Iop Conference, 2017, 81:012054.

5. Wang Y, Lee K, Liu D, et al. Environmental impact and recovery of the Bohai Sea following the 2011 oil spill[J]. Environmental Pollution, 2020, 263(Pt B): 114-343.

6. Carmo D, Antunes J, Pinho, et al. Oil Spills in Coastal Zones: Predicting Slick Transport and Weathering Processes[J]. Open Ocean Eng. J., 2010, 3(3):129-142.

7. J. Antunes do Carmo, J.L. Pinho, J.P. Vieira. Oil Spills in Coastal Zones: Predicting Slick Transport and Weathering Processes[J]. Open Ocean Eng. J., 2010, 3:129-142.

8. Kameleh Aghajanloo, Moharam Dolatshahi Pirooz. The Simulation of the Oil Weathering Processes in Marine Environment[J]. 2011 International Conference on Environmental and Computer Science, 2011,19.

9. Xue J, Yu Y, Bai Y, et al. Marine Oil-Degrading Microorganisms and Biodegradation Process of Petroleum Hydrocarbon in Marine Environments: A Review[J]. Current Microbiology, 2015,71(2):220228.

10. Stephanie E. Chang, Jeremy Stone, Kyle Demes and Marina Piscitelli. Consequences of oil spills: a review and framework for informing planning[J]. Ecology and Society, 2014,19(2):26.

11. Mostafawi N. How severely was the Persian Gulf affected by oil spills following the 1991 Gulf War?[J]. Environmental Geology, 2001, 40(10):1185-1191.

12. Yafeng, Guiqin, Zhiguo, et al. Research on the Assessment Method of Oil Spill Environmental Risks of Offshore Oil Facilities[J]. Aquatic Procedia, 2015.

13. Han Y, Nambi I M, Clement T P . Environmental impacts of the Chennai oil spill accident-A case study[J]. Sci. Total Environ., 2018, 626:795-806. 
14. Okandan E, F Gümrah, Demiral B . Importance of assessment of oil pollution along Black Sea coast and Bosphorous Strait-Turkey[C]// International Seminar on Nuclear War \& Planetary Emergencies Session. 2001.

15. Liu X, Wirtz K W . Decision making of oil spill contingency options with fuzzy comprehensive evaluation[J]. Water Resour. Manag.,2007,21(4): 663-676.

16. Lang $\mathrm{Y} \mathrm{H}$, Cheng $\mathrm{F} \mathrm{F}$, Wang $\mathrm{N} \mathrm{N}$. Fuzzy Comprehensive Evaluation of Oil Spills Pollution Level for Offshore Platform[J]. Appl. Mech. Mater., 2011, 71-78:3012-3015.

17. Zhou J, Xu L. The Damage Assessment of Marine Oil Spill Pollution Using Back-Propagation Neural Network[J]. Energy Procedia, 2011, 11:3116-3121.

18. Han D, Wang G Y, Zang T Y . Application of Fuzzy Decision Theory in the Oil-Gas Field Production and Management[J]. Appl. Mech. Mater., 2014, 488489:1297-1300.

19. Mil'Shtein L M . Comprehensive Evaluation and Selection of Separators for the Oil and Gas Industry $[\mathrm{J}]$. Chemical \& Petroleum Engineering, 2014, 49(11-12):727-735.

20. Fingas $M$. Weather Effects on Oil Spill Countermeasures[J]. Oil Spill Science and Technology, 2011:339-426.

21. Dong Y . Factors influencing marine oil spills and cleanup operations[J]. Journal of Dalian Maritime University, 2009(S1):40-42.

22. Hongjun, You, Hongjie, et al. Forecasting the yield of oil field gas with the fuzzy comprehensive evaluation method and the genetic algorithm[J]. Chemical Technology, 2014, 9(1):4-7.

23. Zhao J , Jin J, Zhu J, et al. Water Resources Risk Assessment Model based on the Subjective and Objective Combination Weighting Methods[J]. Water Resour. Manag., 2016, 30(9):3027-3042.

24. Chan H K, Wang X . Hierarchical Model in Decision Making[J]. Fuzzy Hierarchical Model for Risk Assessment, 2013, 25-43.

25. Solnes J . Environmental quality indexing of large industrial development alternatives using AHP[J]. Environ. Impact Assess. Rev., 2003, 23(3):283-303.

26. Sahoo S , Dhar A, Kar A . Environmental vulnerability assessment using Grey Analytic Hierarchy Process based model[J]. Environ. Impact Assess. Rev., 2016, 56(JAN.):145-154.

27. Zhang J Y, Wang L C . Assessment of water resource security in Chongqing City of China: What has been done and what remains to be done? [J]. Nat. Hazards, 2015, 75(3):2751-2772.

28. Kang C , Feng J , Zheng Y . Study on Oil and Gas Pipeline Risk Assessment Based on Entropy Weight Fuzzy Comprehensive Evaluation Method[J]. Journal of Liaoning Shihua University, 2015, 35(5):27-30, in Chinese.
29. Wang X L, Xiao J Z . Multi-objective dynamic programming for the optimal operation of natural gas production and sales[J]. Computer \& Communication Technologies in Agriculture Engineering International Confe, 2010, 3:240-243.

30. Lang $\mathrm{Y}$ H, Cheng F F, Wang N N. Fuzzy Comprehensive Evaluation of Oil Spills Pollution Level for Offshore Platform[J]. Appl. Mech. Mater., 2011,71-78:3012-3015.

31. Hao X, Xiao F . Fuzzy Synthetic Evaluation of Gas Station Safety[C]// Fuzzy Information and Engineering 2010 - Volume I, Proceedings of the 5th Annual Conference on Fuzzy Information and Engineering, ACFIE 2010, Sepember 23-27, 2010, Huludao, China. Springer Berlin Heidelberg, 2010.

32. Liang D, Liu D, Pedrycz W, et al. Triangular fuzzy decision-theoretic rough sets[J]. Int. J. Approx. Reasoning, 2013, 54(8):1087-1106.

33. Wang J, Liu C, Feng J , et al. Literature review of the effects of petroleum hydrocarbons on marine phytoplankton[J]. Environmental Pollution \& Control, 2011, 33(4):81-86.

34. Paul J H, Hollander D, Coble P, et al. Toxicity and mutagenicity of gulf of Mexico waters during and after the deepwater horizon oil spill.[J]. Environmental Science \& Technology, 2014, 48(6):3591-2.

35. Bejarano A C, Michel, et al. Oil spills and their impacts on sand beach invertebrate communities: A literature review $[\mathrm{J}]$. Environmental Pollution, 2016,218(Nov.):709-722.

36. Zhou S D, Zheng F Z, Li T . Analysis on the Factors Influencing the Kinematic Viscosity of Petroleum Products[J]. Advanced Materials Research, 2012, 459:386-389.

37. Lefebvre-Chalain, Hélèn. Fifteen Years of Particularly Sensitive Sea Areas: A Concept In Development[J]. Ocean and Coastal Law Journal, 2016, 13(1):3-3.

38. Isah $\mathrm{M} \mathrm{N}$. The role of environmental impact assessment in Nigeria's oil and gas industry[J]. Waste Manage., 2012, 32(10):1989-1998.

39. 39. Mark A. Zacharias, Edward J. Gregr.Sensitivity and Vulnerability in Marine Environments: an Approach to Identifying Vulnerable Marine Areas[J]. Conserv. Biol.,2005,19(1):86-97.

40. Kawarada H, Baba E, Suito H . Effect of spilled oil on coastal ecosystems[C]// Proceedings of Fifth China-Japan Seminar on Numerical Mathematics. Department of Urban Environment Systems Chiba University, 1-33 Yayoicho, Inage-ku, Chiba 26385SS, Japan, 2002

41. Deborah F M, Beegle-Krause C J, Rowe J , et al. Oil Spill Risk Assessment-Relative Impact Indices by Oil Type and Location[J]. Asascience Com, 2009.

42. Kankara R S , Arockiaraj S , Prabhu K . Environmental sensitivity mapping and risk 
assessment for oil spill along the Chennai Coast in India[J]. Mar. Pollut. Bull., 2016, 106(1-2):95-103.

43. Li F, Zhang H, Chen L, et al. Influencing Factors of Oil Slick Movement on Tidal Rivers[C]// International Conference on Bioinformatics \& Biomedical Engineering. IEEE, 2008.

44. Beegle-Krause C J , Lehr W J . Oceanographic and Meteorological Effects on Spilled Oil[M]. Handbook of Oil Spill Science and Technology, 2015:301-310.

45. Stringari C E, Marques W C, Mello L, et al. Modeling the wind influence in an oil spill along the southern Brazilian shelf[J].Engenharia Térmica (Thermal Engineering), 2012,11(1-2):100-109.

46. Brovchenko I, Kuschan A, Maderich V, et al. The modelling system for simulation of the oil spills in the Black Sea[J]. Oceanography, 2003, 69:586-591.

47. Schwartzberg H G . The movement of oil spills[J]. International Oil Spill Conference Proceedings, 1971(1):489-494.

48. Murray S P . The Effects of Weather Systems, Currents, and Coastal Processes on Major Oil Spills at Sea[J]. Pollut. Transfer Transp. Sea, 2018(2):169227.

49. Hellmann $\mathrm{H}$. Influence of water temperature on the behavior of floating crude oil[J]. Erdoel \& Kohle, Erdgas, Petrochemie,1973,26(9):513-517.

50. Reisbig R L . Oil Spill Drift Caused by the Coupled Effects of Wind and Waves[R]. Missouri Univ-Rolla Div of Engineering Research, 1973.

51. Bechtel R D, Wickley-Olsen E, Boufadel M C, et al. The movement of oil at sea due to irregular waves[J]. International Oil Spill Conference Proceedings, 2008(1):943-947.

52. Liu H, Xiao Y, Gao X . Study on Environmental Supervision of Marine Oil Spill Pollution[J]. Ecological Economy, 2018,34(7):185-189, in Chinese.

53. Weiwei J, Wei A, Yupeng Z, et al. Research on Evaluation of Emergency Response Capacity of Oil Spill Emergency Vessels[J]. Aquatic Procedia, 2015, 3:66-73, in Chinese.

54. Zhao Y W, Yang Z F. Integrative fuzzy hierarchical model for river health assessment: A case study of Yong River in Ningbo City, China[J]. Commun. Nonlinear Sci. Numer. Simul., 2009, 14(4):17291736.

55. Alonso J A, Ma T L . A Statistical Criterion of Consistency in the Analytic Hierarchy Process[J]. International Conference on Modeling Decisions for Artificial Intelligence, 2005.

56. Alonso J A, Lamata M T . Consistency in the analytic hierarchy process: a new approach[J]. Int. J. Uncertainty Fuzziness Knowl.-Based Syst., 2006, 14(4):445-459.

57. Lowen $\mathrm{R}$. Categorical methods and techniques in fuzzy mathematics[J]. Fuzzy Sets Syst., 1999, 104(3): 357.
58. Jiang X, Bao Z, Wang L . The coupled method Fuzzy-AHP applys to solve multi-criteria decision making problems. World Scientific and Engineering Academy and Society (WSEAS), 2009,8(11).

59. Wang J Q, Li X E, Chen X H . Hesitant Fuzzy Soft Sets with Application in Multicriteria Group Decision Making Problems[J]. Sci. World J.,2015:806-983.

60. Oil spill in Penglai 19-3 Oilfield[EB/OL]. https://www.conocophillips.com.cn/zh/ke-chi-xu-fazhan/zhi-li-yu-bo-hai-de-zhang-qi-fa-zhan/penglai19-3you-tian-yi-you-shi-jian/

61. State Oceanic Administration announces investigation of oil spill accident in Penglai 19-3 Oilfield[EB/OL].http://www.gov.cn/gzdt/201107/05/content_1899673.htm

62. The platform fault of Suizhong 36-1 oilfield of CNOOC has been eliminated and the oil film is being cleaned[EB/OL].https://www.chinanews.com/ny/20 11/07-13/3177919.shtml

63. Zhang Q, Liu L, Pan B Y, et al. Marine oil-spill pollution assessment model based on fuzzy comprehensive evaluation[J].Marine Science,2016,40(5):97-102, in Chinese.

64. Liu Jie. Research on the method of the level assessment of oil spill pollution on Bohai offshore platform[D]. Ocean University of China, 2010, in Chinese. 